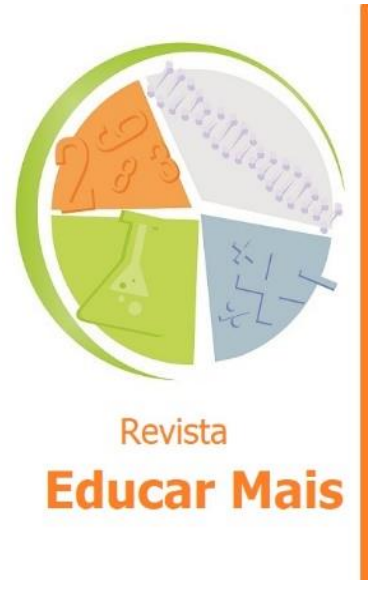

\title{
Um tutorial para utilização de videoaulas como organizadores prévios de uma aprendizagem significativa
}

\author{
A tutorial for using video classes as previous organizers of meaningful \\ learning
}

\section{Tutorial para usar las clases de video como organizadores previos de aprendizaje significativo}

Glayce Helena Barbosa Alves ${ }^{1}$; Débora Leite Silvano²

\section{RESUMO}

O presente estudo teve como objetivo auxiliar professores a desenvolverem videoaulas como organizadores prévios no processo de ensino de Ciências da Natureza. A proposta fundamenta-se teoricamente na Teoria da Aprendizagem significativa de David Ausubel e na contribuição das Tecnologias da Informação e Comunicação na sala de aula. Para tal, foi desenvolvido um vídeo tutorial contendo conceitos de organizador prévio, mapas conceituais, storyboard e roteiro, que demonstra a importância das videoaulas como conteúdo de ensino e apresenta sugestões de cursos de produção. A coleta de dados foi realizada mediante questionário aplicado durante realização de um workshop online, para avaliação da efetividade do produto educacional, no formato de um vídeo tutorial, aos alunos do Curso de Licenciatura em Biologia (Instituto Federal de Brasília). Concluímos que o vídeo tutorial poderá ser uma ferramenta digital útil para que os professores se apropriem das informações nele contidas e elaborem as suas próprias videoaulas com viés na Teoria da Aprendizagem Significativa, aliada ao conhecimento tecnológico como ferramenta de ensino.

Palavras-chave: Tecnologias da Informação e Comunicação; Mapa conceitual; Storyboard; David Ausubel.

\begin{abstract}
This study aimed to help teachers develop video classes as previous organizers in the teaching process of Nature Sciences. The proposal is theoretically based on David Ausubel's Theory of Meaningful Learning and on the contribution of Information and Communication Technologies in the classroom. To this end, a video tutorial was developed containing concepts of previous organizer, concept maps, storyboard and script, which demonstrates the importance of video classes as teaching content and presents suggestions for production courses. Data collection was carried out through a questionnaire applied during an online workshop to assess the effectiveness of the educational product, in the form of a tutorial video, to students of the Biology Degree Course (Federal Institute of Brasilia). We conclude that video tutorials can be a useful digital tool for teachers to appropriate the information contained in it and develop their own video classes with a bias in the Meaningful Learning Theory, combined with technological knowledge as a teaching tool.
\end{abstract}

Keywords: Information and Communication Technologies; Concept map; Storyboard; David Ausubel.

\footnotetext{
${ }^{1}$ Graduada em Pedagogia, Especialista em Administração Escolar e Mestra em Educação Profissional e Tecnológica. Professora efetiva da Secretaria de Estado de Educação do Distrito Federal, Brasília/DF - Brasil. E-mail: glaycehelenab@edu.se.df.gov.br

${ }^{2}$ Licenciada em Ciências Biológicas e Mestra e Doutora em Ecologia. Professora do Instituto Federal de Brasília (IFB) e do Programa de Mestrado Profissional em Educação Profissional e Tecnológica (ProfEPT), Brasília/DF - Brasil. E-mail: debora.silvano@ifb.edu.br
} 


\section{RESUMEN}

Este estudio tuvo como objetivo ayudar a los profesores a desarrollar videoclases como organizadores previos en el proceso de enseñanza de las Ciencias de la Naturaleza. La propuesta se basa teóricamente en la Teoría del Aprendizaje Significativo de David Ausubel y en la contribución de las Tecnologías de la Información y la Comunicación en el aula. Para ello, se desarrolló un video tutorial que contiene conceptos de organizador previo, mapas conceptuales, storyboard y guión, que demuestra la importancia de las video clases como contenido didáctico y presenta sugerencias para cursos de producción. La recolección de datos se realizó a través de un cuestionario aplicado durante un taller en línea para evaluar la efectividad del producto educativo, en forma de video tutorial, a estudiantes de la Licenciatura en Biología (Instituto Federal de Brasilia). Concluimos que los videotutoriales pueden ser una herramienta digital útil para que los docentes se apropien de la información contenida en ellos y desarrollen sus propias videoclases con un sesgo en la Teoría del Aprendizaje Significativo, combinado con el conocimiento tecnológico como herramienta didáctica.

Palabras clave: Tecnologías de la información y la comunicación; Mapa conceptual; Storyboard; David Ausubel.

\section{INTRODUÇÃO}

A pandemia do novo Coronavírus (Covid-19), no ano de 2020, trouxe consequências devastadoras para as diferentes esferas da sociedade, no Brasil e no mundo, impactando diretamente na convivência social dos diferentes grupamentos humanos, incluindo a escola, cujas aulas foram suspensas por períodos prolongados em algumas localidades. Para reduzir os impactos da suspensão das aulas presenciais no tocante ao processo ensino-aprendizagem, a maioria dos sistemas educacionais teve que se reinventar introduzindo aulas remotas com a utilização das tecnologias disponíveis.

Neste novo contexto, de aulas remotas ou de aulas à distância, as tecnologias da comunicação e informação (TIC), que já eram utilizadas na educação, porém de forma tímida (SANTOS; OLIVEIRA; GALVÃO, 2016), tornaram-se grandes aliadas dos professores, ora como suporte para a utilização de recursos de ensino e aprendizagem, a exemplo da plataforma Moodle, ora como o próprio recurso, a exemplo das videoaulas.

As videoaulas, mediadas pelo professor, podem tornar-se um recurso de ensino eficaz para a facilitação de aprendizagens significativas, seja em aulas remotas ou presenciais, desde que o conteúdo a ser ensinado encontre ressonância com os conhecimentos já existentes na estrutura cognitiva do educando (CARAMANO, 2017). Neste contexto, a presente pesquisa orientou-se pela hipótese de que as videoaulas, usadas como organizadores prévios no processo de ensino, potencializam a aprendizagem significativa.

O conceito de aprendizagem significativa, central na teoria de David Ausubel, considera que o fator que mais influencia a aprendizagem é aquilo que o aprendiz já sabe (MOREIRA, 2017). Podemos considerar que esta ideia se refere ao conteúdo total e à organização das ideias do sujeito, ou, em um contexto de aprendizagem de um determinado assunto, relaciona-se ao conteúdo e às ideias do sujeito sobre essa área específica de conhecimentos (MOREIRA, 2017). Assim, uma das condições para que se tenha uma aprendizagem significativa é que o material a ser aprendido seja potencialmente significativo. Outra condição é que o educando tenha predisposição a aprender. 
Organizadores prévios, segundo Moreira e Masini (2007, p. 21), "são materiais introdutórios apresentados antes do próprio material a ser aprendido" cuja "principal função é servir de ponte cognitiva entre o que o aprendiz já sabe e o que ele deve saber, a fim de que o material possa ser aprendido de forma significativa".

Neste sentido, as videoaulas podem ser utilizadas como organizadores prévios para auxiliar o educando a encontrar sua realidade, mas com foco sobre o que se espera que ele desenvolva nos momentos presenciais, na compreensão do caminho a ser percorrido durante as atividades que deve realizar, num processo de ensino e aprendizagem mais significativo (CARAMANO, 2017).

De acordo com a Base Nacional Comum Curricular (BRASIL, 2017, p. 16), "contextualizar os conteúdos dos componentes curriculares, identificando estratégias para apresentá-los, representálos, exemplificá-los, conectá-los e torná-los significativos" é uma das ações que visam "assegurar as aprendizagens essenciais" na Educação Básica. Ao nosso ver esse é o grande desafio para a maioria dos educadores, que podem se instrumentalizar através da formação inicial ou da formação continuada.

Em relação à formação inicial, as Diretrizes Curriculares Nacionais para a Formação Inicial de Professores para a Educação Básica em conjunto com a Base Nacional Comum para a Formação Inicial de Professores da Educação Básica (BNC-Formação), estabelecem competências gerais docentes que os futuros professores devem adquirir durante o curso, dentre as quais "compreender, utilizar e criar tecnologias digitais de informação e comunicação de forma crítica, significativa, reflexiva e ética nas diversas práticas docentes, como recurso pedagógico e como ferramenta de formação". Além de competências específicas que se referem a três dimensões fundamentais: conhecimento profissional; prática profissional; e engajamento profissional (MEC, 2019, p.13).

Para Machado (2012), a problemática envolta no ensino das ciências diz respeito à dificuldade que os alunos têm em dar significado ao que eles estão aprendendo, provavelmente devido à ausência de conhecimentos prévios presentes na sua estrutura cognitiva. De acordo com Mendes (2010), se o estudante não tiver familiaridade com os conceitos de determinado tema, aumenta a probabilidade de ele construir uma representação mental incorreta. Daí a importância de se utilizar organizadores prévios, conforme previsto na teoria da aprendizagem significativa de David Ausubel.

Partindo da hipótese de que as videoaulas, utilizadas como organizadores prévios no processo de ensino, potencializam a aprendizagem significativa, o presente estudo teve como objetivo auxiliar professores a desenvolverem suas próprias videoaulas a partir desta perspectiva. Assim, apresentamos um vídeo tutorial para elaboração de videoaulas, para que os professores e futuros professores possam vislumbrar a possibilidade de criarem seus próprios vídeos, caso a proposta encontre ressonância nas suas práticas educativas.

\section{REFERENCIAL TEÓRICO}

\subsection{Aprendizagem Significativa}

A teoria da aprendizagem significativa, como ficou conhecida a "teoria cognitiva de aprendizagem verbal significativa", desenvolvida por David Ausubel e apresentada em 1963, surgiu em oposição à aprendizagem verbal por memorização, em voga nas décadas de 1960 e 1970. 
De acordo com Ausubel, Novak e Hanesian (1980, p. 133) "a aprendizagem significativa ocorre quando a nova informação é adquirida através do esforço deliberado por parte do aluno de relacionar a nova informação com os conceitos ou proposições relevantes preexistentes na estrutura cognitiva".

O material de aprendizagem potencialmente significativo e a predisposição do aluno para aprender são condições essenciais para a ocorrência da aprendizagem significativa (AUSUBEL; NOVAK; HANESIAN, 1980; MOREIRA, 2012; MOREIRA; MASINI, 2007):

A aprendizagem significativa processa-se quando o material novo, ideias e informações que apresentam uma estrutura lógica, interagem com os conceitos relevantes e inclusivos, claros e disponíveis na estrutura cognitiva, sendo por eles assimilados, contribuindo para sua diferenciação, elaboração e estabilidade (MOREIRA; MASINI, 2007, p.15).

De acordo com Moreira e Masini (2007, p. 29) "à medida que a aprendizagem significativa ocorre, conceitos são desenvolvidos, elaborados e diferenciados em decorrência de sucessivas interações".

Aquilo que o aprendiz já sabe é, na visão de Ausubel, a variável isolada mais importante para a aprendizagem significativa de novos conhecimentos. Segundo Ausubel, Novak e Hanesian (1980, prefácio), "descubra o que ele sabe e baseie nisso os seus ensinamentos".

Moreira (2006) esclarece que "aquilo que o aprendiz já sabe" não se trata da ideia de "pré-requisito", que é muito comum de se ouvir no ambiente escolar. Trata-se daquelas ideias, conceitos e proposições, isto é, dos conteúdos mínimos já presentes na sua estrutura cognitiva que, posteriormente, poderão servir como ponto de "ancoragem" ao novo conhecimento. A este conhecimento, especificamente relevante à nova aprendizagem, que permite ao aprendiz dar significado a um novo conhecimento que lhe é apresentado, Ausubel denominou de "conceito subsunçor", "subsunçor" ou "ideia-âncora" (MOREIRA, 2012; MOREIRA; MASINI, 2007).

Para a ocorrência da aprendizagem significativa é necessário identificar os conceitos básicos da matéria de ensino e como eles são estruturados. Para que isso ocorra, Ausubel, Novak e Hanesian (1980) apresentam o princípio da diferenciação progressiva, o princípio da reconciliação integrativa, a organização sequencial e a consolidação.

De acordo com estes autores, no princípio da diferenciação progressiva "as ideias mais gerais e mais inclusivas da disciplina são apresentadas em primeiro lugar", sendo "progressivamente diferenciadas, em termos de detalhe e especificidade". Essa ordem corresponde ao modo como o "conhecimento é representado, organizado e guardado no sistema cognitivo humano" ou ainda

Presumivelmente corresponde à sequência natural de aquisição da consciência e sofisticação cognitiva quando os seres humanos são espontaneamente expostos ou a um campo completamente desconhecido do conhecimento ou a um ramo desconhecido de um corpo de conhecimentos familiar (AUSUBEL; NOVAK; HANESIAN, 1980, p. 159).

O desenvolvimento de conceitos é facilitado quando os elementos mais gerais, mais inclusivos de um conceito são introduzidos em primeiro lugar e, posteriormente então, este é progressivamente diferenciado, em termos de detalhe e especificidade. Este processo Ausubel denominou de princípio da diferenciação progressiva, para o qual propôs duas hipóteses (MOREIRA; MASINI, 2007, p. 29):

a) é mais fácil para o ser humano captar aspectos diferenciados de um todo mais inclusivo previamente aprendido, do que chegar ao todo pelas suas partes diferenciadas; 
b) a organização do conteúdo de uma certa disciplina, na mente de um indivíduo, é uma estrutura hierárquica na qual as ideias mais inclusivas estão no topo da estrutura e, progressivamente, incorporam proposições, conceitos e fatos menos inclusivos e mais diferenciados (MOREIRA; MASINI, 2007, p. 30-31).

O princípio da diferenciação progressiva foi introduzido como um processo integrante da estrutura cognitiva no qual conceitos e proposições seguem uma estrutura hierárquica de cima para baixo, sendo apresentados no início da instrução e progressivamente diferenciados ao longo dela (MOREIRA 2006).

Para levar a efeito o princípio da diferenciação progressiva na organização e programação do conteúdo Ausubel, Novak e Hanesian (1980, p. 160) propõem a utilização de "organizadores iniciais", que de acordo com Moreira (2006, p. 23) "sirvam de ancoradouro para o novo conhecimento e levem ao desenvolvimento de conceitos subsunçores que facilitem a aprendizagem subsequente".

Quando o material instrucional é programado para explorar relações entre conceitos, apontar similaridades e diferenças significativas, reconciliando discrepâncias reais ou aparentes temos o princípio da reconciliação integrativa (MOREIRA; MASINI, 2007). Isso ocorre quando "elementos existentes na estrutura cognitiva com determinado grau de clareza, estabilidade e diferenciação são percebidos como relacionados, adquirem novos significados e levam a uma reorganização da estrutura cognitiva" (MOREIRA, 2009, p. 8), conforme o exemplo:

É o que ocorreria, por exemplo, se o aluno tivesse conceitos de campo elétrico e magnético claros e estáveis na estrutura cognitiva, os percebesse intimamente relacionados e reorganizasse seus significados de modo a vê-los como manifestações de um conceito mais abrangente, o de campo eletromagnético (MOREIRA, 2009, p. 8-9).

Tanto a diferenciação progressiva quanto a reconciliação integrativa são princípios que integram o processo de aprendizagem significativa.

$\mathrm{Na}$ programação do conteúdo para fins instrucionais a organização sequencial dos tópicos ou unidades de estudo deve observar as relações de dependência naturalmente existentes entre eles na matéria de ensino, e bem assim, os princípios da diferenciação progressiva e da reconciliação integrativa, sem deixar de considerar a "disponibilidade de ideias-âncoras relevantes na estrutura cognitiva para a aprendizagem significativa e a retenção" (MOREIRA, 2006, p. 178).

Porém, antes que novos materiais sejam introduzidos é necessário garantir a consolidação ou maestria, que significa domínio do que está sendo estudado, isso pressupõe que o "tópico ou unidade precedente seja aprendido de maneira clara, estável e organizada" de acordo com a "premissa básica de que o fator isolado mais importante influenciando a aprendizagem é o que o aluno já sabe" (Idem).

\subsubsection{Organizadores Prévios}

Organizadores prévios são materiais introdutórios apresentados em um nível mais alto de abstração, generalidade e abrangência, antes do próprio material a ser aprendido, cuja principal função é servir de ponte cognitiva entre o que o aluno já sabe sobre um assunto ou conteúdo e o que ele precisa saber para poder dar significado aos conceitos, princípios e ideias do novo material de aprendizagem (MOREIRA, 2006; MOREIRA; MASINI, 2007). 
De acordo com Moreira e Masini (2007, p. 21) "o uso de organizadores prévios é uma estratégia proposta por Ausubel para, deliberadamente, manipular a estrutura cognitiva a fim de facilitar a aprendizagem significativa".

Organizadores prévios estabelecem relações explicitas entre o novo conhecimento e os conhecimentos que já estavam presentes na estrutura cognitiva do aluno, contribuindo para sua diferenciação, elaboração e estabilidade, além de contribuir para que o tópico ou unidade precedente seja aprendido de maneira clara, estável e organizada (MOREIRA, 2006; MOREIRA; MASINI, 2007).

Organizadores prévios são mais eficientes quando apresentados no início das tarefas de aprendizagem, do que quando introduzidos simultaneamente com o material a ser aprendido, pois dessa forma suas "propriedades integrativas" ficam salientadas (MOREIRA; MASINI, 2007) e 0 aprendiz consegue perceber que novos conhecimentos estão relacionados às ideias apresentadas anteriormente, ou a subsunçores que existem em sua estrutura cognitiva prévia (MOREIRA, 2012).

Moreira (2006 p. 137) apresenta dois tipos de organizadores, dos quais os professores podem lançar mão para desenvolverem as estratégias de ensino com vistas à aprendizagem significativa:

a) um "organizador comparativo" pode ser formulado quando da aprendizagem de material relativamente familiar para estabelecer relações entre ideias, proposições e conceitos já existentes na estrutura cognitiva e aqueles contidos no material de aprendizagem;

b) um "organizador expositivo" pode ser formulado para a "aprendizagem de material relativamente não familiar" a fim de fornecer "ideias âncora" relevantes para a aprendizagem significativa do novo material.

Um organizador do tipo "expositivo" deve ser "formulado em termos daquilo que o aprendiz já sabe em outras áreas de conhecimento" a fim de "suprir a falta de conceitos, ideias ou proposições relevantes à aprendizagem desse material" (MOREIRA, 2006).

Para cada uma das unidades a ensinar devem ser construídos organizadores específicos (MOREIRA; MASINI, 2007), os quais podem ser apresentados em formato de texto, de uma discussão, de uma demonstração, de um filme, de um vídeo (MOREIRA, 2006), de um enunciado, uma pergunta, uma situação-problema, uma demonstração, uma leitura introdutória, uma simulação, uma aula que precede um conjunto de outras aulas.

As possibilidades são muitas, mas a condição é que preceda a apresentação do material de aprendizagem e que seja "mais abrangente, mais geral e inclusivo" do que este, razão pela qual não é recomendado apresentar um sumário ou um resumo que geralmente estão no mesmo nível de abstração do material a ser aprendido (MOREIRA, 2012).

\subsection{O Papel das TIC na Educação e das Videoaulas para a aprendizagem significativa.}

Embora o acesso, uso e apropriação das tecnologias da informação e da comunicação encontre barreiras para sua implementação em muitas escolas, por uma série de fatores, dentre os quais encontram-se aqueles presentes na pesquisa TIC Educação 2018 (CGI.BR, 2019): a obsolescência ou ausência de equipamentos e dispositivos para uso pedagógico; ausência de formação dos docentes sobre o uso e integração das TIC no processo de ensino e de aprendizagem; e, a falta ou baixa qualidade da conexão à Internet, verifica-se o esforço de um contingente significativo de docentes e 
gestores escolares que realizam ações no sentido de integrar as tecnologias às práticas pedagógicas, inclusive valendo-se da utilização de equipamentos, dispositivos, softwares e conexão de rede próprias.

Para Tarouco (2019, p. 34), o indivíduo "fluente digital" é "aquele que usa, compreende e sabe sobre tecnologia da informação". Mas, ela reconhece que para um professor chegar neste nível, além das iniciativas pessoais, deve haver um esforço coletivo contínuo (escola, governo e instituições) capaz de promover soluções de formação colaborativa destinada a melhorar e desenvolver a competência profissional digital da categoria.

No documento Base Nacional Comum para a Formação Inicial de Professores da Educação Básica (BNC-Formação), dentre as habilidades exigidas para os docentes, referente à competência "planejar ações de ensino que resultem em efetivas aprendizagens", encontra-se: "utilizar as tecnologias digitais, os conteúdos virtuais e outros recursos tecnológicos e incorporá-los à prática pedagógica, para potencializar e transformar as experiências de aprendizagem dos estudantes e estimular uma atitude investigativa" (MEC, 2019, p. 17).

Significa dizer que estamos diante de um quadro irreversível, para o qual são exigidas competências e habilidades docentes que coadunam com as exigências atuais da sociedade tecnológica e científica, na qual toda a comunidade escolar está imersa, especialmente os estudantes e as estudantes que, segundo Rojo e Moura (2012), "são todos falantes nativos da linguagem digital dos computadores, vídeo games e internet. Por isso Moran (2012, p.34) defende que "a educação escolar precisa compreender e incorporar mais as novas linguagens, desvendar os seus códigos, dominar as possibilidades de expressão e as possíveis manipulações".

Kenski (2003, p. 91) define as tecnologias como "ferramentas que auxiliam as pessoas a viverem melhor dentro de um determinado contexto social e espaço-temporal", ao mesmo tempo em que esclarece que a preocupação dos educadores precisa ser a de contribuir para a formação de pessoas ativas socialmente, e que possam ter autonomia e conhecimento suficientes para a compreensão e análise crítica do papel das novas tecnologias no atual momento da sociedade.

Para Zacariotto (2012, p. 7), a tecnologia "é uma ferramenta poderosa de comunicação e construção de conhecimentos entre professores e alunos". Neste sentido ele elenca um rol de possibilidades com a utilização das TIC como ferramenta de apoio pedagógico: facilita a colaboração, a comunicação e a execução de inúmeras tarefas com a utilização dos seus recursos; auxilia na adoção de novas formas de ensinar, mais práticas e mais próximas da sociedade; colabora e permite novos caminhos e soluções para sanar as deficiências de ensino; serve de apoio ao professor com as mídias, som, imagens, filmes, pesquisas, promovendo a criatividade e o estímulo aos alunos.

Neste contexto o professor é o "profissional que desenvolve, implementa inovações e participa ativamente e criticamente do processo". É ele quem "proporciona aos alunos a mediação, o encontro com a realidade, e articula novos saberes, transmitindo e ensinando simultaneamente a cada nova aula", por isso "a tecnologia não irá, em nenhum momento, substituir a figura do professor" (ZACARIOTTO, 2012, p. 15). Para o autor, "a tecnologia educacional é apenas uma ferramenta, como caderno e lápis; se não houver um professor para ensinar a escrever, ninguém aprende e o caderno se perde no tempo" (ZACARIOTTO, 2012, p. 22).

Corroborando com a afirmativa acima, Moran (2012, p. 2) advoga que "não são os recursos que definem a aprendizagem, são as pessoas, o projeto pedagógico, as interações, a gestão". O professor 
é o mediador entre a proposta de ensino e o que "os alunos esperam, desejam e realizam". Ainda que um aluno nem precise ir à escola para conseguir uma informação que está em uma mídia portátil, irá recorrer ao professor para interpretá-la, relacioná-la, hierarquizá-la, contextualizá-la (MORAN, 2007).

Um exemplo do papel do professor mediador foi visto durante o período em que as escolas em todo o mundo globalizado estiveram fechadas por conta da pandemia do novo Coronavírus (Covid-19), no ano de 2020 e meados de 2021. Para amenizar a ausência das aulas presenciais, governos e instituições colocaram à disposição aplicativos e plataformas para a realização das aulas e encontros remotos. Mas o processo de ensino e a promoção das aprendizagens somente foi possível porque professores e equipes de apoio ao ensino assumiram a responsabilidade de dar continuidade às atividades escolares utilizando-se das ferramentas tecnológicas disponíveis. Grande parcela, inclusive, superando-se, promoveu o que Rojo (2017, p. 1) chama de "aprendizagem interativa", combinando o "currículo da letra e do impresso aos multiletramentos e novos letramentos contemporâneos", também conhecido como "webcurrículo", o qual exige interação, colaboração e protagonismo entre todas dos envolvidos no processo.

Nas aulas de Biologia as TIC, especialmente as mídias digitais, tornam-se uma ferramenta de apoio pedagógico de grande valia, pois, é uma área de ensino fortemente dominada pelas imagens, que também estão presentes no cotidiano dos alunos. E as imagens são o principal atrativo das mídias sociais (Instagram, Tik Tok, WhatsApp, YouTube), especialmente as imagens em movimento que combinadas com o som, compõem o que conhecemos como audiovisual, pois são elas que atraem a atenção dos internautas, em sua maioria alunos de instituições de ensino, e tornam os conteúdos publicados atrativos e interessantes.

Nossos alunos estão envoltos em uma sociedade cercada por imagens e representações icônicas da realidade, por isso o audiovisual (televisão, cinema, computador e vídeo), como forma de conhecimento imagético, tem se mostrado muito significativo para eles, pois permite que compreendam os conteúdos de "maneira sensitiva e não apenas diante das argumentações da razão que o professor apresenta" (ARROIO; DINIZ; GIORDAN, 2005, p. 2).

Segundo Moran (1995) o vídeo aproxima a sala de aula do cotidiano, pois parte do concreto, do visível, do imediato, próximo, que toca todos os sentidos, permitindo segundo ele $(2012$, p. 67$)$ "ao professor agir com questionamentos, problematizações, discussões, elaboração de sínteses, aplicados ao dia a dia escolar".

Arroio e Giordan (2006) apresentam duas funções para o vídeo/videoaula: a "função informativa exclusiva" que o torna capaz de transmitir informações, servir de reforço da explicação prévia do professor e meio de avaliação; e a "função investigativa" que entra em cena quando o professor "oferece aos alunos um guia de leitura do vídeo antes de exibi-lo", para que extraiam as informações pertinentes e após a exibição retomem as discussões sobre o assunto abordado.

De acordo com Rosa (2000, p. 39) o audiovisual no ensino de Ciências tem como função: motivar; demonstrar; servir como organizador prévio; ser instrumento para a diferenciação progressiva e para a reconciliação integrativa; ser instrumento de apoio à exposição do professor; e simular experiências.

No caso específico da presente pesquisa vamos nos ater ao audiovisual no formato de vídeo/videoaula, devido ao seu caráter didático e pedagógico, com a possibilidade de reconstrução 
do conhecimento para vários contextos e realidades, auxiliando alunos e professores a darem significado à linguagem escrita através da linguagem imagética, interativa e multimodal.

\section{PROCEDIMENTOS METODOLÓGICOS}

A pesquisa foi desenvolvida no Campus Planaltina, do Instituto Federal de Brasília. Devido à temática do presente estudo, escolhemos a turma do sexto semestre do Curso de Licenciatura em Biologia para participar da pesquisa. A escolha foi proposital, levando-se em consideração que a turma estava cursando a disciplina Prática de Ensino V, que teria como um de seus objetivos a utilização de mídias digitais no ensino da disciplina Biologia e, entre as atividades, a elaboração de roteiros e produção e apresentação de videoaulas, com viés de desenvolvimento integral e de aprendizagem significativa.

A coleta de dados foi realizada mediante questionário, com questões fechadas e abertas, aplicado durante realização de um workshop online, para avaliação da efetividade do produto educacional, no formato de um tutorial para elaboração de videoaulas como organizador prévio. O workshop foi realizado em junho de 2021, através de videoconferência pelo aplicativo Google Meet

\subsection{Elaboração do Produto Educacional (PE)}

O Produto Educacional é um vídeo tutorial para a produção de videoaulas como organizadores prévios. O vídeo contém 13 cenas interligadas, com tempo de duração de 4'38'. Apresenta os conceitos de organizador prévio, mapas conceituais, storyboard, roteiro; demonstra a importância das videoaulas como conteúdo de ensino; apresenta sugestões de cursos de produção de videoaulas localizados no YouTube; e, também, sugestões de videoaulas encontradas no YouTube que podem ser utilizadas como organizadores prévios.

$\mathrm{Na}$ etapa de pré-produção foram desenvolvidas as ações que antecederam a produção do Vídeo Tutorial. Como exemplos de ferramentas de planejamento da videoaula, foram apresentados o mapa conceitual e o roteiro, também chamado de script ou escopo de vídeo.

O mapa conceitual na presente pesquisa tem como propósito servir como recurso didático para estabelecer as relações hierárquicas entre os conceitos que devem ser utilizados na produção das videoaulas, ressaltando seu papel de organizador prévio expositivo de acordo com o princípio da diferenciação conceitual progressiva. Nele um conceito é relacionado ao outro através de linhas intermediadas por palavras-chave, formando uma proposição, e esta evidencia o significado da relação conceitual, ou seja, das estruturas conceituais que estão sendo ensinadas.

O roteiro é o instrumento utilizado na produção audiovisual para guiar a equipe técnica envolvida e oferecer melhor visualização de tudo o que deve ser feito durante a produção e a pós-produção da videoaula. No roteiro se definem as cenas ou as sequências, a descrição dos personagens, as ações e os diálogos e o cenário.

Cada produção audiovisual possui o seu formato de roteiro, mas alguns elementos são obrigatórios a todos: o cabeçalho, a coluna de cena, a coluna do áudio, a coluna do vídeo, a coluna do lettering.

a) Na coluna da cena deve-se escrever o número da cena ou sequência numérica, seguindo a cronologia dos atos. 
b) Na coluna do áudio escreve-se o texto que será falado na cena, pelo apresentador ou pelo narrador, indicando se ao "vivo" ou em "off".

c) Na coluna do vídeo são descritas todas as ações que serão realizadas durante a gravação ou na edição do vídeo: o que precisa aparecer no enquadramento; os efeitos sonoros e seu tempo de inserção; e, os movimentos de câmera.

d) Na coluna do lettering deve-se escrever o texto que aparecerá no vídeo em forma de narrativa escrita com objetivo de identificar um diálogo, rotular uma cena ou identificar pessoas. Se houver será acrescentado quando da edição do vídeo.

Para transformar as ideias contidas no roteiro em conteúdo imagético usamos o storyboard, que nada mais é do que uma sequência de planos desenhados, como se fosse uma história em quadrinhos. Esses quadros de cena recebem notas sobre o que deve acontecer e ser transmitido ao público.

Na Figura 1 apresentamos as primeiras cenas do storyboard criado para o vídeo tutorial, produzido no PowerPoint, utilizando as ilustrações do banco de imagens Pixabay.com, Shutterstock.com, Depositphotos.com, Canva.com, VideoScribe. As capturas de tela para o Screencast (movimento de tela) foram feitas no Software Movavi Screen Record.

Na fase da produção, utilizamos o software de edição de vídeos Adobe Premiere, fazendo uso de imagens, vídeos e áudios produzidos para esta finalidade. O áudio do vídeo tutorial foi captado no aplicativo de gravação de voz do celular, sendo, posteriormente, transferido para o software livre de edição digital de áudio Audacity (https://www.audacityteam.org/), para a edição, quando retiramos os ruídos e equalizamos a voz.

\subsection{Aplicação e avaliação do Produto Educacional}

O workshop foi o mecanismo utilizado para implementar a pesquisa, tendo ocorrido dentro do cronograma de aulas previstas para a turma. Na ocasião, após esclarecimentos sobre o objetivo do presente estudo, apresentamos o vídeo tutorial e, em seguida, os alunos e o professor da turma responderam ao questionário enviado para o e-mail de cada um, com total liberdade para questionamentos. Após, realizamos uma conversa coletiva sobre o tutorial apresentado, ocasião em que foi possível contribuir apresentando sugestões para o desenvolvimento dos vídeos que a turma teria que apresentar como parte das atividades da disciplina.

O questionário composto por questões fechadas e abertas foi desenvolvido no Google Forms, sendo dividido em duas partes: a primeira, contendo oito questões para análise da relação dos participantes com os vídeos/videoaulas durante a trajetória escolar pessoal e como docente; e a segunda, contendo sete questões para avaliação da efetividade do tutorial para produção de videoaulas como organizadores prévios. Nesta última parte, as questões foram elaboradas a partir dos eixos e descritores avaliativos criados por Leite (2018), para quem os materiais educacionais devem ser elaborados "a partir de metodologia que contemple aspectos comunicacionais, pedagógicos, teóricos e críticos". Dentre os eixos, selecionamos aqueles que se enquadrariam à presente pesquisa, quais sejam: estética e organização; estilo de linguagem; conteúdo; e criticidade apresentada no material educativo. 
Figura 1 - Storyboard do vídeo tutorial

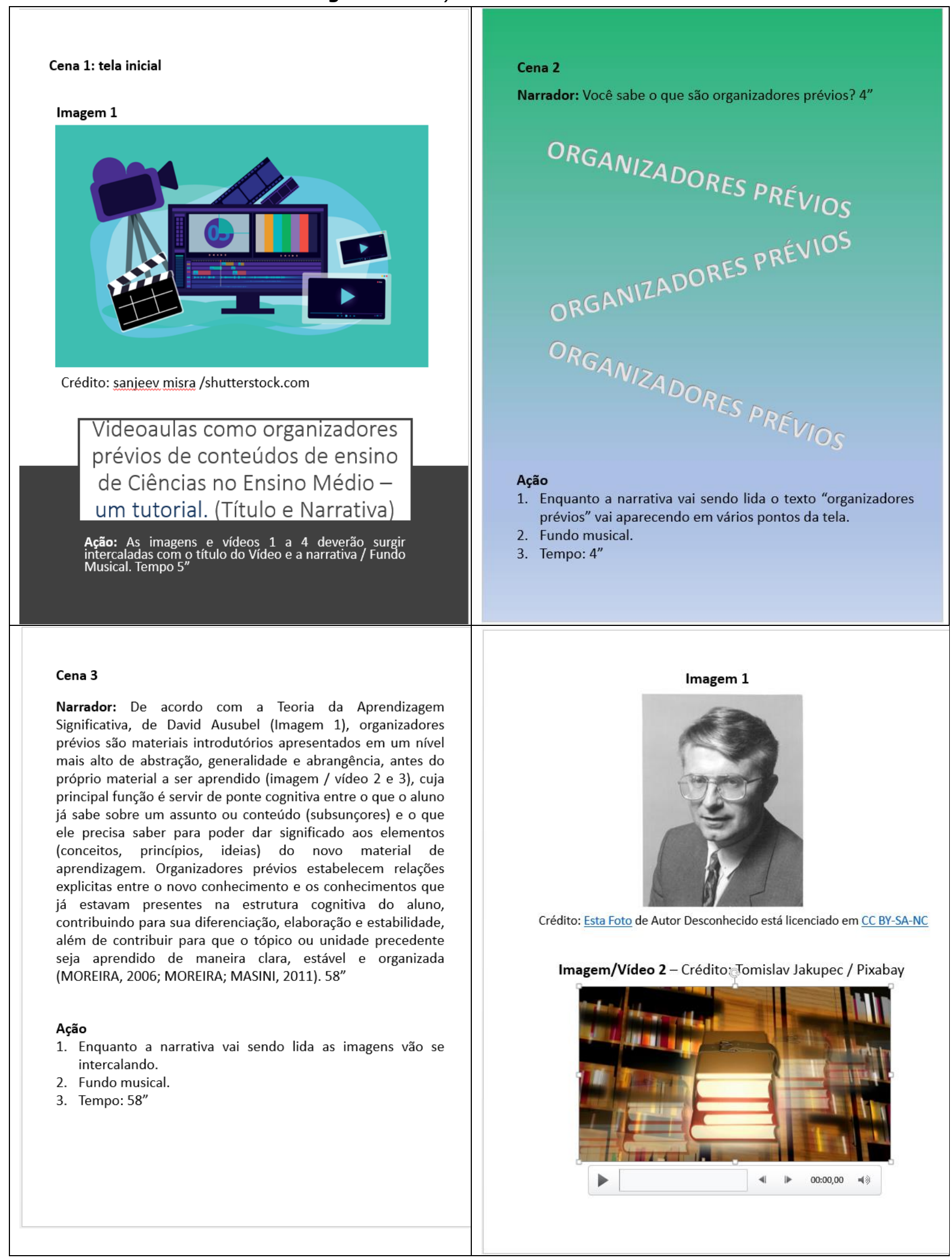

Fonte: Elaborado pelo autor 
Para cada eixo, selecionamos da proposta de Leite (2018) alguns descritores em forma de afirmativas, como consta no Quadro 1.

Quadro 1 - Relação eixo / descritor.

\begin{tabular}{l} 
A - Estética e organização do material educativo \\
A1 - O embasamento teórico do material está em consonância com a forma escolhida para se \\
comunicar com o espectador. \\
A2 - Os recursos escolhidos ou a combinação entre estes contribuem para melhor abordar o \\
assunto, do ponto de vista da imagem e som. \\
\hline B - Estilo de linguagem apresentado no material educativo \\
B1 - A narração é feita de maneira atrativa e de fácil compreensão. \\
B2 - O tutorial apresenta conceitos e argumentos claros e de fácil entendimento. \\
B3 - O tutorial explica todos os termos e expressões técnicas. \\
\hline C - Conteúdo apresentado no material educativo \\
C1 - O conteúdo pode ser adaptado para ser utilizado na produção de outra videoaula. \\
\hline D - Criticidade apresentada no material educativo \\
D1 - Propõe reflexão sobre a prática educativa.
\end{tabular}

Fonte: Adaptado de Leite (2018)

Cada um destes eixos e descritores foi pensado no sentido de avaliar se o produto educacional pode se constituir como um roteiro para a construção de outras videoaulas como organizadores prévios. De acordo com Arroio e Giordan (2006, p. 9), ao lançarmos mão de um recurso audiovisual como um vídeo, por exemplo, de antemão é necessário analisar "qual a linguagem do produto, os gêneros discursivos veiculados e se o nível em que as ideias estão enunciadas se adapta a outros contextos".

Esta análise é necessária porque no caso concreto desta pesquisa, apontamos para uma série de etapas que devem ser seguidas por quem futuramente irá desenvolver o próprio vídeo, adaptado ao seu contexto. Assim, o principal questionamento no caso do tutorial é: será que o conteúdo pode ser adaptado para ser utilizado na produção de outra videoaula? A resposta aos descritores nos levará a desvelar este questionamento.

\section{RESULTADOS E DISCUSSÃO}

A aplicação do produto educacional foi realizada durante um workshop com professores em formação, alunos da disciplina Prática de Ensino V (curso de Licenciatura em Biologia), que tem como foco a utilização de videoaulas. Estes alunos já se encontram ao final da segunda metade do curso e muitos já cursaram as disciplinas de Estágio em Docência.

Ao serem questionados se já atuam como docente ou se fizeram estágio em algum dos níveis da Educação Básica, a maioria dos participantes $(n=5)$ declarou já atuar como docente. Apenas três ainda não possuem experiência como docentes da Educação Básica. A pertinência da pergunta reside no fato de que neste primeiro bloco objetivamos estabelecer a relação entre vídeo/videoaula e suas trajetórias, seja como estudante, seja como docente, o que irá auxiliar na compreensão das demais questões. 
A maioria dos participantes $(n=6)$ costuma utilizar vídeos em suas aulas. Apenas dois participantes não utilizam vídeos em suas aulas, sendo aqueles que ainda não atuam na docência.

Quanto à pergunta referente à frequência com que os participantes utilizam vídeos/videoaulas em suas aulas (Figura 2), as respostas variaram entre 'mensalmente' $(n=3)$, 'anualmente' $(n=2)$ ou 'não se aplica' $(n=2)$. Apenas um participante respondeu que utiliza vídeos uma vez por semana em suas aulas.

Figura 2 - Resposta dos participantes com relação à frequência com que utilizam vídeos em suas aulas.
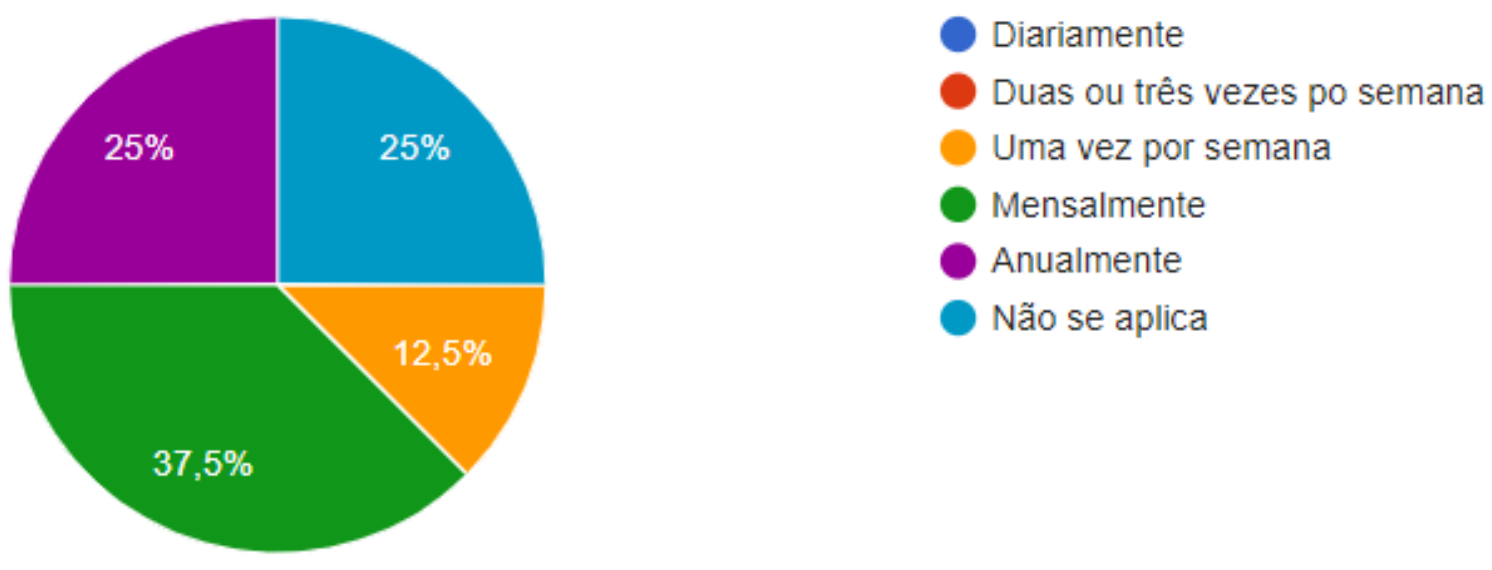

Fonte: Elaborado pelo autor

Quando o questionamento diz respeito à finalidade com a qual os participantes utilizam os vídeos em sala de aula (Figura 3), a maioria $(n=6)$ utiliza os vídeos com finalidade de ministrar um conteúdo. As demais respostas estiveram relacionadas à utilização para entretenimento, enriquecer o conteúdo ministrado ou exemplificar uma atividade. Quanto à utilização como organizador prévio não houve quem se manifestasse.

Figura 3 - Resposta dos participantes quanto à finalidade da utilização dos vídeos em sala de aula.

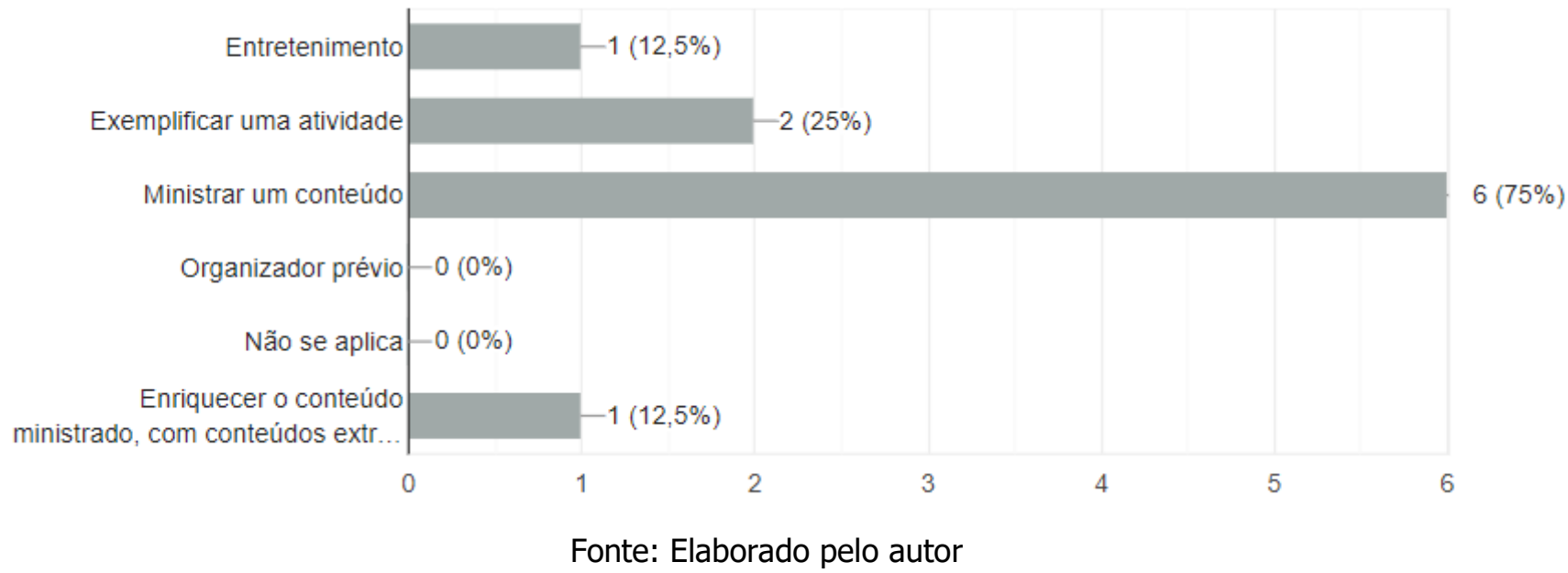

Quando questionados se a utilização do vídeo na sua trajetória escolar, enquanto estudante facilitou a compreensão dos conteúdos de ensino, os dados revelam que a maioria dos participantes $(87,5 \%)$ concorda ou concorda totalmente.

Os dados acima têm relação com o uso do vídeo como ferramenta didática em nossas escolas, que é relativamente recente (década de 1990), como resultado da criação de políticas públicas que traziam 
no seu bojo a utilização das TIC. Dentre estas, a Lei no 9.394/96 (BRASIL, 1996), também conhecida como a Lei de Diretrizes e Bases da Educação Nacional (LDB), foi um marco no sentido de incentivar o uso das TIC na escola, integradas à ciência e ao mundo do trabalho. Trouxe ainda previsão de educação a distância ou educação presencial mediada por tecnologias, o que já era habitual em outros países. A partir dela foram sendo criados outros mecanismos legais, incentivando a criação de políticas públicas de incentivo ao uso das TIC como facilitadora do processo de ensino e aprendizagem, tendo principalmente o professor como alvo. Além disso, a partir dos anos 2000 ocorreu a expansão e universalização da Internet aliada à entrada no mercado dos grandes conglomerados tecnológicos que passam a criar aplicativos, sites, plataformas e softwares destinados, dentre outros, à produção, armazenamento e veiculação de mídias digitais.

E foi nesta esteira que o vídeo e as videoaulas, como ferramentas didáticas, começaram a ganhar espaço no processo de ensino da educação formal. Esta afirmativa coaduna com a pesquisa sobre o uso das tecnologias de informação e comunicação nas escolas brasileiras (TIC Educação 2018), a qual indica a universalização do acesso à Internet e o uso mais intenso das tecnologias entre professores (CGI.BR, 2019).

A pesquisa TIC Educação 2018 também revela que quase a totalidade dos professores das escolas públicas (97\%) mencionaram já ter utilizado conteúdos obtidos na Internet para a preparação de aulas ou atividades com os alunos, na maioria das vezes utilizando seus próprios dispositivos. O que chama a atenção é que o conteúdo mais utilizado são as imagens. Entretanto, a utilização de filmes ou animações e videoaulas também se demonstra significativa (CGI.BR, 2019).

A citada pesquisa também revela os entraves que dificultam a utilização dos vídeos e videoaulas com maior frequência na sala de aula, como por exemplo dificuldades de compartilhamento da rede de dados na escola; dificuldade para realizar a transposição didática do material que baixaram ou copiaram da Internet; a ausência de competências para utilizar programas de criação e produção de conteúdo; dificuldade para orientar os alunos sobre o uso seguro do computador, do celular e da Internet; e ausência na escola de equipamentos e de softwares licenciados para criação de conteúdos educacionais (CGI.BR, 2019).

Por isso, iniciativas como a inclusão de disciplinas específicas para tratar do desenvolvimento de competências digitais na formação inicial docente, a exemplo da Prática de Ensino V, do curso de Licenciatura em Biologia do Instituto Federal Brasília, coadunam com as instruções e normas previstas nas novas Diretrizes Curriculares Nacionais para a Formação Inicial de Professores para a Educação Básica, editada em 2019 e, com certeza, irão instrumentalizar os futuros professores das habilidades necessárias para aliarem o conhecimento cientifico e o conhecimento tecnológico em prol do ensino, inclusive promovendo reflexões e orientações sobre o uso crítico desses recursos por parte dos alunos.

Verificamos que $100 \%$ dos respondentes concordam ou concordam plenamente que o vídeo/videoaula pode ser uma estratégia de ensino eficaz para uma aprendizagem significativa dos conteúdos a serem trabalhados.

Uma mídia digital pode se "constituir em uma poderosa ferramenta para o ensino, se for trabalhado de maneira contextualizada e interdisciplinar" (SANTOS; ARROIO, 2009, p. 11) e, se além de informar sobre um tema específico, permitir abordagens múltiplas e interdisciplinares (MORAN, 1995), por isso 
ela deve "ter uma função definida no plano de ensino elaborado pelo professor para um dado conteúdo" (ROSA, 2000, p. 34) e valorizar os alunos como sujeitos do processo de ensino.

E para promover aprendizagens significativas é necessário que o conteúdo e as abordagens presentes no vídeo/videoaula "sejam um instrumento de leitura da realidade e facilitadora da aquisição de uma visão crítica dela" (CHASSOT, 2018, p.131), bem como, encontrem ressonância com aquilo que os alunos já sabem sobre determinado assunto ou tema, para que sirvam como gatilho para a compreensão científica da matéria de ensino.

Quando questionados se seus conhecimentos sobre a produção de videoaulas são satisfatórios (Figura 4), a metade dos participantes $(n=4)$ concordam ou concordam totalmente. Três participantes declaram possuir um conhecimento parcial e apenas um demonstra pouco conhecimento discordando parcialmente.

Figura 4 - Resposta dos participantes ao serem questionados se seus conhecimentos sobre a produção de videoaulas são satisfatórios, sendo 1 (um) para discordo totalmente e 5 (cinco) para concordo plenamente.

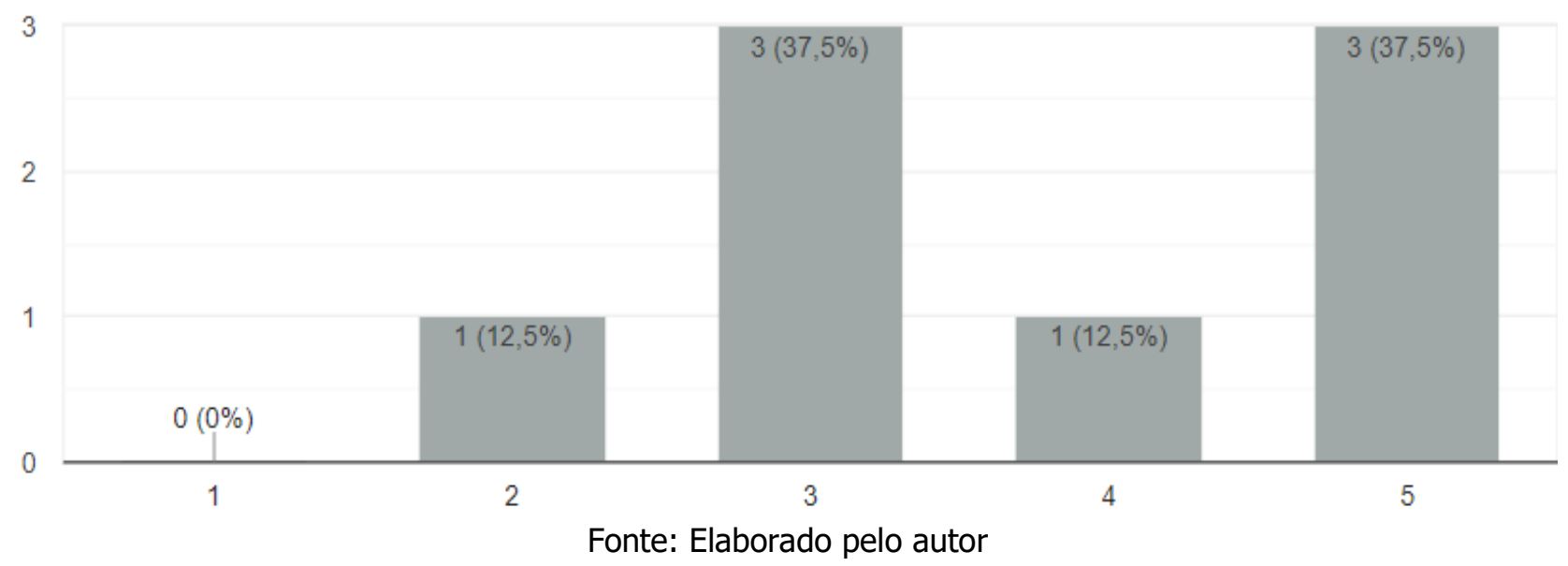

Com relação à avaliação do tutorial para produção de videoaulas como organizadores prévios, todos os participantes concordam ou concordam plenamente (100\%) que o embasamento teórico do tutorial está em consonância com a forma escolhida para se comunicar com o espectador, conforme primeiro descritor (A1) do eixo estética e organização do material educativo.

O mesmo pôde ser observado na avaliação do segundo descritor (A2) do eixo estética e organização do material educativo. Neste aspecto, todos os participantes concordam ou concordam totalmente que os recursos escolhidos ou a combinação entre estes contribuem para melhor abordar o assunto, do ponto de vista da imagem e som.

Na avaliação do primeiro descritor (B1) do eixo estilo de linguagem apresentado no material educativo, $100 \%$ dos participantes concordam totalmente que a narração do vídeo tutorial é feita de maneira atrativa e de fácil compreensão.

Quanto ao segundo descritor (B2) do eixo estilo de linguagem apresentado no material educativo. Todos concordaram ou concordaram totalmente que o tutorial apresenta conceitos e argumentos claros e de fácil entendimento. O mesmo resultado foi obtido na avaliação terceiro descritor (B3), do eixo estilo de linguagem apresentado no material educativo, todos os participantes concordam ou concordam totalmente que o tutorial explica todos os termos e expressões técnicas. 
$\mathrm{Na}$ avaliação do descritor $\mathrm{C} 1$, do eixo conteúdo apresentado no material educativo, todos os participantes concordam totalmente que conteúdo pode ser adaptado para ser utilizado na produção de outra videoaula.

Por fim, na avaliação do eixo criticidade apresentada no material educativo, 87,5\% dos participantes concordam totalmente que o tutorial propõe reflexão sobre a prática educativa. Este aspecto vem ao encontro de nossa expectativa inicial quando do planejamento do produto educacional, onde esperávamos que os profissionais que se confrontassem com o produto educacional pudessem refletir a respeito das estratégias de ensino empregadas, ao tempo em que pensassem em alternativas que contemplassem as TIC para viabilizar uma aprendizagem significativa.

Os eixos e descritores propostos por Leite (2018) foram utilizados para avaliar e validar o vídeo tutorial, pois, conseguem abarcar as especificidades do produto educacional proposto evidenciando os aspectos que colocamos em relevância. De acordo com Leite (2018, p. 336) estes eixos "foram pensados para abarcar, tanto reflexões sobre a estética e organização do material educativo, quanto sobre os conteúdos e propostas de cada capítulo, mostrando a indissociabilidade entre forma e conteúdo", razão pela qual orienta que tanto a produção quanto a avaliação dos produtos educacionais seja realizados a partir de metodologia que contemple aspectos comunicacionais, pedagógicos, teóricos e críticos e, que sejam validados a partir de eixos e descritores específicos.

Neste sentido, após a análise dos dados a que se referem os eixos e descritores utilizados na presente pesquisa, concluímos que o produto educacional intitulado Videoaulas como organizadores prévios de conteúdos de ensino de Ciências no Ensino Médio - um tutorial atingiu o seu objetivo e pode ser usado como um tutorial para que outros educadores possam pensar a produção de videoaulas como organizadores prévios.

\section{CONSIDERAÇÕES FINAIS}

A prática professoral precisa ser confrontada de tempos em tempos, para que no chacoalhar dos pensamentos e ideias já arraigadas, haja uma mutação para a transformação.

Como o produto aqui apresentado trata-se de um Objeto de Aprendizagem (OA), possui como características a Flexibilidade e a Reusabilidade, podendo ser adaptado para diferentes contextos de aprendizagem.

Porém, desde já esclarecemos que nossa pretensão não foi ensinar técnicas de edição de áudio e vídeo, já que demandam tempo para aprendizado e seriam necessários muitos vídeos para chegarmos ao resultado final. Mas tão somente apresentar um panorama geral do que são os organizadores prévios e do papel das videoaulas como estratégia de ensino para a promoção da alfabetização científica e de aprendizagens significativas; apresentar o passo a passo em nível de pré-produção de como fazer a seleção dos temas/conteúdos e o inter-relacionamento entre conceitos, utilizando mapas conceituais; como elaborar o roteiro e o storyboard que subsidiarão a produção das videoaulas; apresentar o tripé composto por áudio, vídeo e iluminação, os quais darão forma às videoaulas; apresentar vídeo tutorais e cursos disponibilizados no YouTube com as técnicas de produção de videoaulas, além de exemplos de vídeos prontos que podem ser utilizados em sala de aula como organizadores prévios.

As TIC são ferramentas que tem contribuído com o ensino em todos os níveis, especialmente no 
período da pandemia provocada pelo novo coronavírus, quando precisamos nos reinventar como educadores para dar conta do "novo normal" em educação. Aliadas ao projeto pedagógico, ao plano de ensino e ao planejamento de aula, oferecem recursos e ferramentas que podem potencializar a alfabetização científica e a aprendizagem significativa.

Sendo assim, concluímos que a estratégia de utilizar um manual em formato de vídeo tutorial para a produção de videoaulas como organizadores prévios poderá ser uma ferramenta digital útil para que outros professores se apropriem das informações nele contidas e, no contexto de suas práticas, elaborem as suas próprias videoaulas com viés na Teoria da Aprendizagem Significativa e na Alfabetização Científica, aliando o conhecimento científico e o conhecimento tecnológico em prol do ensino.

\section{REFERÊNCIAS}

ARROIO, Agnaldo; GIORDAN, Marcelo. O vídeo educativo: aspectos da organização do ensino. Química Nova na Escola, São Paulo, v.24, n.1, p.8-11, nov. 2006.

ARROIO, Agnaldo; DINIZ, Manuela Lustosa; GIORDAN, Marcelo. A utilização do vídeo educativo como possibilidade de domínio da linguagem audiovisual pelo professor de ciências. In: ENCONTRO NACIONAL DE PESQUISA EM EDUCAÇÃO EM CIÊNCIAS - ENPEC, 5., 2005, Bauru. Atas [...]. Bauru: ABRAPEC, 2005.

AUSUBEL, David P.; NOVAK, Joseph D.; HANESIAN, Helen. Psicologia Educacional. Rio de Janeiro: Editora Interamericana, 1980.

BRASIL. Base Nacional Comum Curricular. Ministério da Educação: SEED, 2017.

BRASIL. Lei no 9.394, de 20 de dezembro de 1996. Estabelece Diretrizes e Bases para a Educação Nacional. Diário Oficial da União, Brasília, DF, p. 27833, 23 dez. 1996. Disponível em http://www.planalto.gov.br/ccivil_03/leis/19394.htm Acesso em 07/09/2019

CARAMANO, Elana Simone Schiavo. Proposta de videoaulas como organizadores prévios para uma aprendizagem significativa no ensino de inglês na EJA. 2017. Dissertação (Mestrado em Docência para a Educação Básica) - Universidade Estadual Paulista Júlio de Mesquita Filho, Bauru, 2017.

CGI.BR. Pesquisa sobre o uso das tecnologias de informação e comunicação nas escolas brasileiras: TIC Educação 2018. São Paulo: Comitê Gestor da Internet no Brasil, 2019. Disponível em: https://cetic.br/media/docs/publicacoes/216410120191105/tic_edu_2018_livro_eletronico.pdf Acesso em: 03 ago. 2021.

CHASSOT, Áttico. Alfabetização científica: questões e desafios para a educação. 8. ed. Ijuí: Editora UNIJUÍ, 2018.

KENSKI, Vani M. Novas tecnologias na educação presencial e a Distância I. In: BARBOSA, Raquel Lazzari Leite (Org). Formação de Educadores: desafios e perspectivas. São Paulo: Editora Unesp, 2003. p. 91-107.

LEITE, Priscila Souza Chisté. Produtos Educacionais em Mestrados Profissionais na Área de Ensino: uma proposta de avaliação coletiva de materiais educativos. In: CONGRESSO IBERO-AMERICANO EM INVESTIGAÇÃO QUALITATIVA - CIAIQ, 7., 2018, Fortaleza. Atas [...]. Fortaleza: Ludomedia, 2018, p. 330-339. 
MACHADO, Maria Helena. Uso do vídeo como ferramenta no ensino de genética. 2012.

Dissertação (Mestrado Profissional em Ensino em Ciências da Saúde e do Meio Ambiente) - Centro Universitário de Volta Redonda - UniFOA, Volta Redonda, 2012.

MEC - Ministério da Educação. Resolução CNE/CP no 2, de 20 de dezembro de 2019. Define as Diretrizes Curriculares Nacionais para a Formação Inicial de Professores para a Educação Básica e institui a Base Nacional Comum para a Formação Inicial de Professores da Educação Básica (BNCFormação). Diário Oficial da União, Brasília, 15 de abril de 2020, Seção 1, pp. 46-49. MENDES, Maximiliano Augusto de Araújo. Produção e utilização de animações e vídeos no ensino de biologia celular para a $1^{a}$ série do ensino médio. Dissertação (Mestrado em Ensino de Ciências) - Universidade de Brasília, Brasília, 2010.

MORAN, José Manuel. Ensino e aprendizagem inovadores com apoio de tecnologias. In: MORAN, José Manuel; MASETTO, Marcos; BEHRENS, Marilda Aparecida (Org.). Novas tecnologias e mediação pedagógica. 19. Ed. São Paulo: Editora Papirus. 2012. p. 11-72.

MORAN, José Manuel. As mídias na educação. In: MORAN, José Manuel. Desafios na Comunicação Pessoal. 3a Ed. São Paulo: Paulinas, 2007, p. 162-166.

MORAN, José Manuel. O vídeo na sala de aula. Comunicação \& Educação, São Paulo, n.2, p. 2735, jan./abr. 1995.

MOREIRA, Marco Antônio; MASINI, Elcie F. Salzano. Aprendizagem significativa: a teoria de David Ausubel. 2. ed. São Paulo: Centauro Editora, 2007.

MOREIRA, Marco Antônio. A teoria da aprendizagem significativa e sua implementação na sala de aula. Brasília: Editora da UnB, 2006.

MOREIRA, Marco Antônio. ¿Al final qué es aprendizaje significativo? Revista Qurriculum, La Laguna, v. 25, p. 29-56, mar. 2012.

MOREIRA. Marco Antônio. Mapas Conceituais, Diagramas V e Organizadores prévios. Porto Alegre: Instituto de Física, UFRGS, 2009. Disponível em https://edisciplinas.usp.br/pluginfile.php/5163390/mod_resource/content/0/DIAGRAMA\%20V.pdf. Acesso em 01 out. 2019.

ROJO, Roxane; MOURA, Eduardo de. Multiletramentos na escola. São Paulo: Parábola Editorial, 2012.

ROJO, Roxane. Entre plataformas, odas e protótipos: novos multiletramentos em tempos de WEB2. The Especialist, v. 38, n. 1, p. 1-20, jan-jul. 2017.

ROSA, Paulo Ricardo da Silva. O uso dos recursos audiovisuais e o ensino de ciências. Caderno Brasileiro de Ensino de Física, Florianópolis, v. 17, n. 1, p. 33-49, abr. 2000.

SANTOS, Priscilla Carmona dos; ARROIO, Agnaldo. A utilização de recursos audiovisuais no ensino de ciências: tendências nos ENPECs entre 1997 e 2007. In: ENCONTRO NACIONAL DE PESQUISA EM EDUCAÇÃO EM CIÊNCIAS - ENPEC, 7., 2009, Florianópolis. Atas [...]. Florianópolis: UFSC, 2009.

SANTOS, Fábio Andrade dos; OLIVEIRA, Rivaldo Araújo de; GALVÃO, Luzia Cristina de Melo Santos. A percepção dos alunos com relação a utilização de recursos tecnológicos no ensino de biologia. In: SIMPÓSIO INTERNACIONAL DE EDUCAÇÃO E COMUNICAÇÃO - SIMEDUC, 7., 2016, Aracajú. Anais [...]. Aracajú: Unit, 2016. 
TAROUCO, Liane Margarida Rockenbach. Competências digitais dos professores. In: CGI.BR. Pesquisa sobre o uso das tecnologias de informação e comunicação nas escolas brasileiras: TIC Educação 2018. São Paulo: Comitê Gestor da Internet no Brasil, 2019. Disponível em: https://cetic.br/media/docs/publicacoes/216410120191105/tic_edu_2018_livro_eletronico.pdf Acesso em: 03 ago. 2021.

ZACARIOTTO, William Antônio. Tecnologia da informação e comunicação em educação. São Paulo: UNIP, 2012. Disponível em https://docplayer.com.br/11445686-Tecnologia-da-informacao-ecomunicacao-em-educacao.html. Acesso em 04 out. 2019.

Submissão: 10/09/2021

Aceito: 04/10/2021 